\title{
A study of dimethyl carbonate conversion and its impact to minimize soot and $\mathrm{NO}$ emissions
}

\author{
María U. Alzueta ${ }^{\text {a }}$, Pablo Salinas ${ }^{\text {a }}$, Ángela Millera ${ }^{a}$, Rafael Bilbao
}

\author{
María Abián ${ }^{\mathrm{a}, \mathrm{b}, *}$
}

a Aragón Institute of Engineering Research $(I 3 A)$, Department of Chemical and Environmental Engineering, University of
Zaragoza, Zaragoza 50018, Spain
${ }^{\mathrm{b}}$ Instituto de Carboquímica (ICB-CSIC), Department of Energy \& Environment, Zaragoza 50018, Spain

\begin{abstract}
Fuel reformulation through the use of oxygenated compounds has been considered as an interesting option both, to reduce the harmful soot emissions and to overcome the dependence on fossil fuels, since many of them are bio-derived fuels. Dimethyl carbonate (DMC) is of interest as oxygenated fuel additive since it presents a relative high oxygen content as compared with other additives and suitable characteristics to be used in combustion systems. The present work includes the analysis of different fundamental aspects of the DMC combustion process: its oxidation behavior (through experimental and computational analysis), its tendency to produce soot and the role of the NO presence in the reaction system. Experiments are performed under well controlled conditions using specifically designed flow reactor systems. Results obtained contribute to extend the available experimental database on DMC, and show the low tendency of DMC to form soot compared to other oxygenates and its capacity to contribute to NO reduction under specific fuel-rich conditions. Modeling calculations are able to reproduce reasonably well the experimental trends observed, and highlight the sensitivity of the results to the thermodynamic data of DMC and DMC derived species.
\end{abstract}

Keywords: DMC; Soot; NO; Oxygenated additives; Combustion

\section{Introduction}

In the line of replacing or minimizing the use of fossil fuels, different alternative fuels such as biofu-

\footnotetext{
* Corresponding author at: Instituto de Carboquímica (ICB-CSIC), Department of Energy \& Environment,

E-mail address: mabian@icb.csic.es (M. Abián).
}

els are of increasing interest in the research community. Particularly, oxygenated compounds, that can be obtained in biorefinery processes, either used directly as fuel or as additives to diesel fuels, can be appropriate to reduce the emissions of soot in diesel engines.

Ren et al. [1] analyzed the influence of blending different oxygenated compounds (esters, ethers and alcohols) with diesel on the combustion and emissions of a diesel engine. The authors observed that, its impact to minimize soot and NO emissions, Proceedings of the Combustion Institute (2016), http://dx.doi.org/10.1016/j.proci.2016.07.086 
14 regardless of the kind of oxygenate additive, soot 15 emissions were decreased, in particular, with the in16 crease of the oxygen mass fraction in the blends, 7 without increasing the $\mathrm{NO}_{x}$ emissions and without 8 reducing engine thermal efficiency. Hydrocarbons 9 (HC) concentrations also decreased with the in20 crease of oxygen mass fraction in the blends. Westbrook et al. [2] conducted a chemical kinetic modeling study of the effects of oxygenated compounds with different functional group on soot emissions from diesel engines, and observed that for the same mass fraction of oxygen, esters were less effective than ethers or alcohols. In this research line, PepiotDesjardins et al. [3] analyzed the influence of the functional group for soot reduction tendency of oxygenated fuels. They highlighted two main factors that can decrease the tendency to form soot precursors: the oxygen content in the molecule and the dilution effect due to the replacement of part of the fuel by less sooting precursor compounds. Other important properties of fuel additives listed by McEnally and Pfefferle [4] to reduce soot are: a small number of carbon atoms in their structure, the presence of interspersed oxygen atoms within the carbon chain and the absence of ramifications. In addition, to obtain a good performance of the fuel-oxygenated additive blend, the cetane number should be around 50-60 and the oxygen weight content in the blend between $10 \%$ and $20 \%$ [5].

Considering these characteristics, dimethyl carbonate (DMC), $\mathrm{CH}_{3} \mathrm{OCOOCH}_{3}$, has been suggested as a promising oxygenated additive to diesel fuels due to its high oxygen content $[6,7]$, the absence of carbon-carbon atomic bonds, suitable boiling point and solubility in diesel fuel [7]. DMC has been also considered as an option for replacing methyl tertiary butyl ether (MTBE) in commercial gasoline to meet with Clean Air Act specification for oxygen in gasoline [8]. In addition to its good properties as an additive to diesel fuels, DMC can be synthesized by transesterification of cyclic carbonates with methanol; and these two components can be obtained from biorefinery processes $[9,10]$.

Preliminary results on the use of DMC as a fuel additive in a diesel engine, equipped with exhaust gas recirculation, suggest that both lower soot and $\mathrm{NO}_{x}$ emissions can occur [e.g. 11]; however, the relative importance of using DMC as an additive on these emissions is unknown. Under laboratory scale conditions, Chen et al. [12] investigated the effect of different oxygenated compounds, including DMC, on laminar premixed low pressure (30 Torr) n-heptane flames. The authors observed an early formation of $\mathrm{CO}_{2}$ in the DMC-doped flame, which was attributed to the decomposition of DMC and its subsequent intermediates. They also concluded that the $\mathrm{C}_{1}-\mathrm{C}_{5}$ hydrocarbon intermediates and benzene concentrations decreased when any of the oxygenated compounds were added to the n-heptane flame.
Although there is evidence that it is possible to add fractions of DMC to both gasoline and diesel fuels maintaining a good engine performance [8], laboratory scale studies regarding this compound are very limited despite the importance of these studies to characterize the reaction scheme involving its conversion process. Therefore, there is a clear need to develop further studies to understand how the oxidation of this compound occurs and to investigate its contribution to the minimization of pollutant emissions.

In 1997, Bilde et al. [13] investigated the atmospheric chemistry of DMC in the $252-370 \mathrm{~K}$ temperature range by using flash photolysis-resonance fluorescence techniques, to address the environmental impact of DMC in the case that it is released into the atmosphere. The authors concluded that, under these conditions, the reactivity of DMC toward $\mathrm{OH}$ radicals is low and is comparable to that of ethane. Subsequently, Sinha and Thomson [14] performed an experimental study of the oxidation of DMC in a diffusion flame, at atmospheric pressure and in the $200-2000 \mathrm{~K}$ temperature range. They outlined that the conversion of DMC produces very low levels of methane, ethane, ethylene, and acetylene, due to the presence of oxygen on the central carbon in DMC that favors the breakage of the $\mathrm{O}-\mathrm{CO}$ bond, forming methoxy radical. The experimental results from this study were further used to develop a chemical kinetic mechanism for DMC oxidation [6]. In this way, Glaude et al. [6] proposed a reaction mechanism for the oxidation of DMC and used it to kinetically analyze its combustion in an opposed flow diffusion flame. They identified the reactions with $\mathrm{H}$ and $\mathrm{OH}$ radicals as the main consumption paths of DMC.

Recently, Hu et al. [15] have published an exper- 110 imental and kinetic modeling study on ignition de- 111 lay times, in the $1100-1600 \mathrm{~K}$ temperature range, 112 for equivalence ratios in the range $\phi=0.5-2.0$. Their 113 results indicate that the DMC is mainly consumed 114 through $\mathrm{H}$ abstraction and that unimolecular de- 115 composition is not relevant under their conditions. 116

To our knowledge, up to date, these are the 117 only studies that address the conversion process of 118 DMC under well-characterized laboratory condi- 119 tions. All of them have been focused on the conver- 120 sion of DMC, both experimental and kinetic mod- 121 eling points of view, but so far the studies have not 122 concentrated on the formation of pollutant emis- 123 sions. Therefore, the present study on the conver- 124 sion of DMC over a wide range of operating con- 125 ditions, and in the presence of NO, provides neces- 126 sary experimental data, both to get insight into the 127 phenomena controlling the process and to improve 128 and update a gas-phase combustion scheme appli- 129 cable in different reaction environments. In partic- 130 ular, emphasizing the impact of DMC addition on 131 the emissions of pollutants, specifically on soot for- 132 mation and NO reduction. 00 103 . 102 104 (n) (x) 08 . (1)

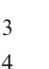

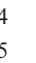
(1) . . (a) . . . 醇 . . . 年 
Table 1

Experimental conditions.

\begin{tabular}{llllllll}
\hline Set & Environment & $\lambda$ & $\mathrm{t}_{\mathrm{r}}(\mathrm{s})$ & {$[\mathrm{DMC}] \mathrm{ppm}$} & {$\left[\mathrm{O}_{2}\right] \mathrm{ppm}$} & {$\left[\mathrm{H}_{2} \mathrm{O}\right] \mathrm{ppm}$} & {$[\mathrm{NO}] \mathrm{ppm}$} \\
\hline $\mathbf{1}$ & Pyrolysis & 0 & 3.09 & 50,000 & 0 & 0 & 0 \\
$\mathbf{2}$ & Fuel-rich & 0.3 & $195 / \mathrm{T}(\mathrm{K})$ & 300 & 300 & 7000 & 500 \\
$\mathbf{3}$ & Fuel-rich & 0.3 & $195 / \mathrm{T}(\mathrm{K})$ & 300 & 300 & 7000 & 0 \\
$\mathbf{4}$ & Fuel-rich & 0.7 & $195 / \mathrm{T}(\mathrm{K})$ & 300 & 630 & 7000 & 500 \\
$\mathbf{5}$ & Fuel-rich & 0.7 & $195 / \mathrm{T}(\mathrm{K})$ & 300 & 630 & 7000 & 0 \\
$\mathbf{6}$ & Stoichiometric & 1 & $195 / \mathrm{T}(\mathrm{K})$ & 300 & 900 & 7000 & 500 \\
$\mathbf{7}$ & Stoichiometric & 1 & $195 / \mathrm{T}(\mathrm{K})$ & 300 & 900 & 7000 & 0 \\
$\mathbf{8}$ & Fuel-lean & 35 & $195 / \mathrm{T}(\mathrm{K})$ & 300 & 31,500 & 7000 & 500 \\
$\mathbf{9}$ & Fuel-lean & 35 & $195 / \mathrm{T}(\mathrm{K})$ & 300 & 31,500 & 7000 & 0
\end{tabular}

* See text for details of the reaction system and experimental procedure of experiment 1.

\section{Experimental}

The experimental installation was specifically designed to obtain data for performing gas-phase chemical-kinetic analysis of the conversion process of gaseous fuels (i.e. hydrocarbons, alcohols, etc.) in different reaction environments. It has been used with success in many previous studies by the group [e.g. 16,17]. The detailed description of the installation can be found elsewhere [18], and therefore only a brief description is given here.

The reaction takes place in a quartz plug-flow reactor, according to the design of Kristensen et al. [19], which is placed in a three-zone electrically heated oven to ensure a uniform temperature profile within $\pm 5 \mathrm{~K}$ throughout the reaction zone. The reaction zone has $8.7 \mathrm{~mm}$ inside diameter and $200 \mathrm{~mm}$ in length. Gases (DMC, $\mathrm{O}_{2}, \mathrm{NO}$ and $\mathrm{N}_{2}$ ) are supplied from gas cylinders through mass flow controllers and $\mathrm{H}_{2} \mathrm{O}$ is fed by saturating a nitrogen stream through a bubbling water system at room temperature; water is added because it is present in most combustion real systems and to minimize the effect of radical recombination in the reactor walls. These gases are supplied in up to four separate streams and mixed just prior to entering the reaction zone. The configuration of the injection system has been designed following the investigations of Alzueta et al. [20].

Experiments of DMC conversion in the absence and presence of $\mathrm{NO}$ were carried out at atmospheric pressure, in the $700-1400 \mathrm{~K}$ temperature range, and with a total flow rate of $1000 \mathrm{~mL}$ (STP)/min using $\mathrm{N}_{2}$ to balance. Considering the volume of the reaction zone and the constant STP flow rate, the residence time of the gases is only function of the reaction temperature in the way of: $\mathrm{t}_{\mathrm{r}}(\mathrm{s})=195 / \mathrm{T}(\mathrm{K})$. The stoichiometry of the reaction $(\lambda)$ is defined as the quotient between the $\mathrm{O}_{2} / \mathrm{DMC}$ ratio available for reaction and the stoichiometric $\mathrm{O}_{2 /} \mathrm{DMC}$ ratio, covering conditions from very fuel-rich $(\lambda=0.3)$ to very fuel-lean $(\lambda=35)$. Table 1 summarizes the experimental conditions tested.
At the outlet of the reaction zone, the reactor 177 has a cooling jacket. Thus, the product gas is ef- 178 ficiently quenched, by means of external refriger- 179 ation with cooling air. The product gas composi- 180 tion has been quantified by continuous $\mathrm{CO}, \mathrm{CO}_{2} 181$ and NO IR analyzers and a gas chromatograph 182 equipped with TCD detector for quantifying hy- 183 drocarbons and oxygenated compounds. The main 184 gases quantified in this study are: $\mathrm{DMC}, \mathrm{CO}, \mathrm{CO}_{2} 185$ and NO (when present), but, depending on the 186 specific operating conditions, also minor concen- 187 trations of $\mathrm{C}_{2} \mathrm{H}_{4}$ and $\mathrm{C}_{2} \mathrm{H}_{6}$ where obtained. The 188 estimated uncertainties in the measurements are 189 $\pm 5 \%$ for both, the continuous IR analyzers and 190 the gas chromatograph, but not less than $10 \mathrm{ppm} .191$ Repeated experiments on different, not consecu- 192 tive, days, showed a good agreement in most of the 193 data points compared (see Fig. 3). The carbon bal- 194 ance was checked for each condition and temper- 195 ature studied and was found to close in general as 196 $95 \pm 10 \%$.

Experiment 1 has been carried out in a different 198 reaction system, which was specifically designed to 199 analyze the formation of soot from different fuels 200 (e.g. [21]). This system is constituted by a quartz 201 flow reactor with a reaction zone of $45 \mathrm{~mm}$ in- 202 side diameter and $160 \mathrm{~mm}$ in length placed into a 203 one-zone electrically heated oven, and a soot col- 204 lection system that includes a quartz fiber filter of 205 $25 \mathrm{~mm}$ diameter and $60 \mathrm{~mm}$ in length, with a mesh 206 size lower than $1 \mu \mathrm{m}$. In this experiment, the re- 207 action system was heated up to $1475 \mathrm{~K}$ in a $\mathrm{N}_{2} 208$ atmosphere before feeding the reactant DMC- $\mathrm{N}_{2} 209$ mixture and, to supply the desired DMC concen- 210 tration to the reactor $(50,000 \mathrm{ppm})$, pure liquid 211 DMC was pumped through the use of an isocratic 212 HPLC pump, subsequently vaporized in a ther- 213 mally insulated line and mixed with the nitrogen. 214 Afterwards, the DMC- $\mathrm{N}_{2}$ mixture was fed into 215 the reaction system (total flow rate of $1000 \mathrm{~mL} 216$ (STP)/min), considering this moment as the ini- 217 tial time for the experiment. The experiment last 218 was $3 \mathrm{~h}$ and, during this time, the soot formed 219 was collected for its subsequent quantification, and 220 
Table 2

Yields to soot $\left(\eta_{\text {soot }}\right)$ from different compounds and mixtures. 50,000 ppm of reactants and $\mathrm{N}_{2}$ to balance, residence time: $3.09 \mathrm{~s}$.

\begin{tabular}{lllllll}
\hline Mixture & $\mathrm{DMC}$ & $\mathrm{C}_{2} \mathrm{H}_{2}$ & $\mathrm{C}_{2} \mathrm{H}_{5} \mathrm{OH}$ & $\mathrm{C}_{2} \mathrm{H}_{2}+10 \% \mathrm{C}_{2} \mathrm{H}_{5} \mathrm{OH}$ & $\mathrm{C}_{2} \mathrm{H}_{2}+20 \% \mathrm{C}_{2} \mathrm{H}_{5} \mathrm{OH}$ & $\mathrm{C}_{2} \mathrm{H}_{2}+40 \% \mathrm{C}_{2} \mathrm{H}_{5} \mathrm{OH}$ \\
\hline O/C (molar) & 1 & - & 0.5 & 0.05 & 0.1 & 0.2 \\
$\eta_{\text {soot }}(\%)$ & 10.2 & 58 & 28.7 & 45 & 39 & 37 \\
Ref. & P.w. & {$[21]$} & {$[29]$} & {$[28]$} & {$[28]$} & {$[28]$} \\
\hline
\end{tabular}

* P.w.: present work.

the product gas composition was analyzed by gas chromatography.

\section{Modeling}

Simulation of the experimental results has been made using a gas-phase chemical kinetic modeling for DMC oxidation process and the Senkin [22], the plug-flow reactor code from the CHEMKIN [23] kinetic-chemical package. The reaction mechanism used is taken from previous works by the authors, described and updated so far [i.e. 16,2427], with the subsequent implementation without modification of the DMC oxidation subset given by Glaude et al. [6]. The full listed mechanism can be found as supplemental material (SMM-1). In general, the thermodynamic data are taken from the same sources as the original mechanisms. However, as it will be seen further below, calculation results have been found to be very sensitive to the thermodynamic data of the DMC subset. Therefore, this aspect will be analyzed and further discussed in the text, and the present limitations to properly simulate DMC conversion are identified.

\section{Results and discussion}

As a first step to evaluate the possible use of DMC as a fuel additive to minimize soot emissions, it is important to assess its tendency to form soot. DMC has no $\mathrm{C}-\mathrm{C}$ bonds in its structure and has a molar $\mathrm{O} / \mathrm{C}$ ratio of 1 , which, in principle, are positive characteristics to generate a minimum amount of soot. 50,000 ppm of DMC in nitrogen were pyrolyzed at a temperature of $1473 \mathrm{~K}$ in a flow reactor (experiment 1 in Table 1). The amount of soot collected was $1.49 \pm 10 \% \mathrm{~g}$, which represents a yield to soot of $10.2 \%$, defined as the percentage of the carbon present in soot compared to the carbon present in the fed gases. Apart from soot, the main gases collected showed the following concentrations: 1169 ppm DMC, 71,338 ppm H $\mathrm{H}_{2}$, 69,173 ppm CO, 10,631 ppm $\mathrm{CO}_{2}, 564 \mathrm{ppm} \mathrm{C}_{2} \mathrm{H}_{4}$, $2464 \mathrm{ppm} \mathrm{C}_{2} \mathrm{H}_{2}, 150 \mathrm{ppm} \mathrm{C}_{6} \mathrm{H}_{6}$, and $6862 \mathrm{ppm}$ $\mathrm{CH}_{4}$.

In order to assess the tendency to form soot by $\mathrm{DMC}$, it is interesting to compare the results of soot formation from DMC and those obtained

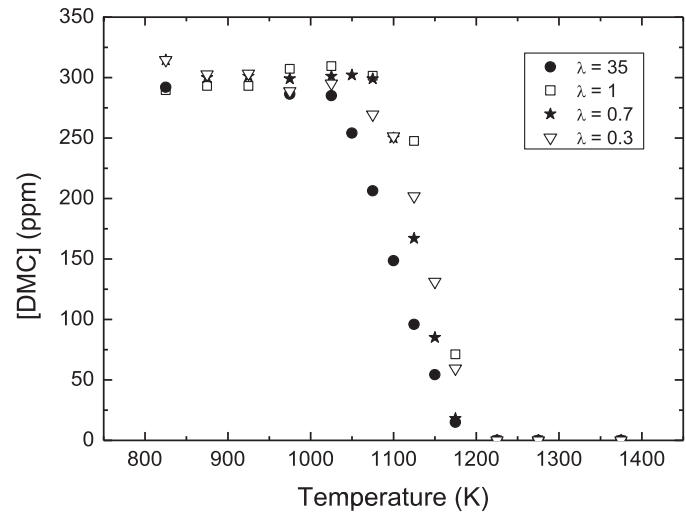

Fig. 1. Conversion of DMC as a function of temperature for different stoichiometries. Inlet conditions correspond to sets 3, 5, 7 and 9 in Table 1 .

under similar experimental conditions with other 265 compounds. Thus, Table 2 shows the yields to soot 266 obtained in the present work, together with liter- 267 ature data on the yield to soot of acetylene (as 268 a well-known soot precursor), ethanol (probably 269 the most studied fuel as additive), and acetylene- 270 ethanol mixtures. The yield to soot obtained in the 271 pyrolysis of DMC is significantly lower compared 272 to the soot obtained in the pyrolysis of ethanol and 273 much lower than in the acetylene case, or in the py- 274 rolysis of the acetylene-ethanol mixtures. This in- 275 dicates that DMC can be a good candidate as fuel 276 additive in relation to soot minimization. 277

In order to further study the conversion of 278 DMC under well-controlled laboratory conditions, 279 experimental results on DMC conversion and CO 280 and $\mathrm{CO}_{2}$ formation as function of temperature and 281 for different stoichiometries are shown in Figs. 1282 and 2 .

As shown in Fig. 1, for fuel-rich $(\lambda=0.3$ and 284 $0.7)$ and stoichiometric $(\lambda=1)$ conditions, the con- 285 version profile of DMC is not significantly influ- 286 enced by the oxygen concentration in the reac- 287 tion environment. Neither the initiation temper- 288 ature nor the temperature window for the DMC 289 consumption are appreciably modified under these 290 conditions. DMC starts reacting at around $1100 \mathrm{~K} 291$ up to be fully consumed at $1200 \mathrm{~K}$. Only for very 292 fuel-lean conditions $(\lambda=35)$, the initial tempera- 293 ture for DMC consumption is shifted $50 \mathrm{~K}$ to lower 294 

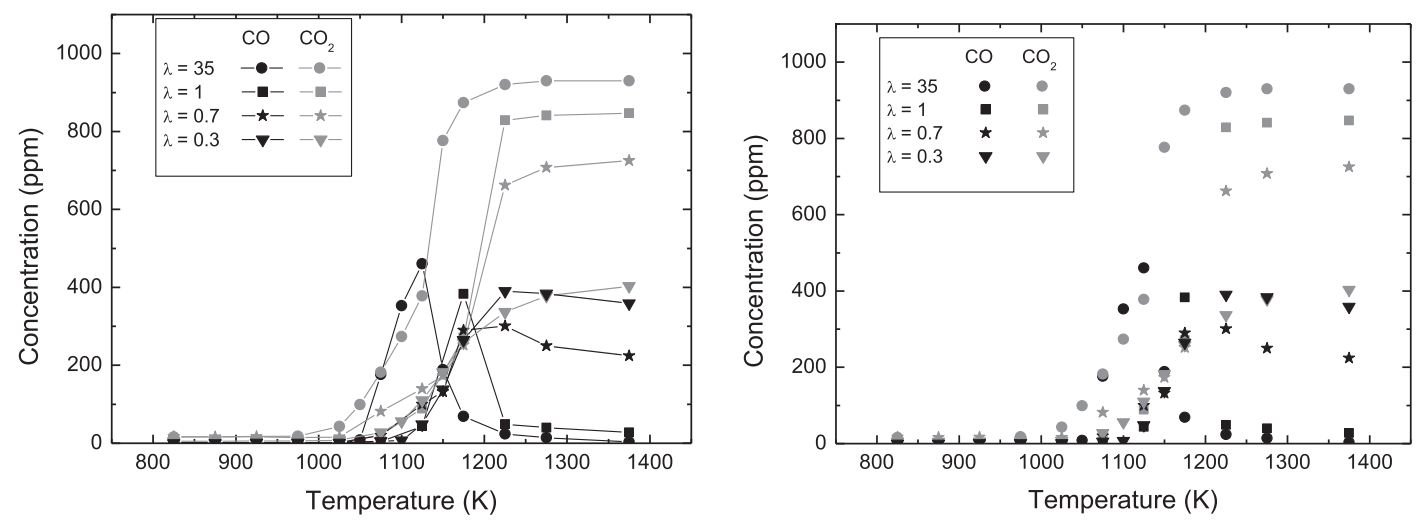

Fig. 2. Experimental evolution of $\mathrm{CO}$ and $\mathrm{CO}_{2}$ from the oxidation of DMC as a function of temperature for different stoichiometries. Inlet conditions correspond to sets 3, 5, 7 and 9 in Table 1.

temperatures, indicating a promotion of the DMC conversion presumably originated by the enhanced oxidation process. The same trend is observed in the formation of $\mathrm{CO}$ and $\mathrm{CO}_{2}$ with temperature (Fig. 2). However, in this case, the specific concentration profiles are influenced by the stoichiometry. The $\mathrm{CO}$ concentration shows a maximum for all the conditions studied, but in general at lower temperatures and of higher magnitude as the oxygen concentration is increased. The formation of $\mathrm{CO}_{2}$ is also enhanced by higher oxygen concentrations.

In order to assess the interaction between DMC and NO, Figs. 3 and 4 show respectively the experimental results of DMC conversion in the absence and presence of $500 \mathrm{ppm}$ of $\mathrm{NO}$, and the concentration of $\mathrm{NO}$ as a function of temperature.

As seen in Fig. 3, the presence of NO does not modify significantly the conversion of DMC under fuel-rich and stoichiometric conditions, while NO promotes the conversion of DMC under very fuel-lean conditions, shifting its conversion profile $200 \mathrm{~K}$ towards lower temperatures. This behavior is related to the NO concentration results of Fig. 4, in which the $\mathrm{NO}-\mathrm{NO}_{2}$ interconversion acts to replenish the $\mathrm{O} / \mathrm{H}$ radical pool, which is responsible for the sensitized oxidation of DMC, as it has been described for a number of fuels (e.g. [30]). For high temperatures and stoichiometric or fuel-rich conditions, the concentration of NO decreases, indicating that under these conditions reburn reactions act to diminish the concentration of NO [20]. Thus, in the presence of typical pollutants present in an engine chamber, such as NO, DMC appears to exhibit a positive behavior. Under fuel-lean conditions, the presence of NO contributes to favor DMC conversion and thus possibly minimizes the formation of soot, because, considering the sensitized oxidation of DMC, any intermediate product originated from DMC conversion will have more time to react. Under fuel-rich conditions, reaction pathway analysis indicates that DMC generates hydrocarbon radi-
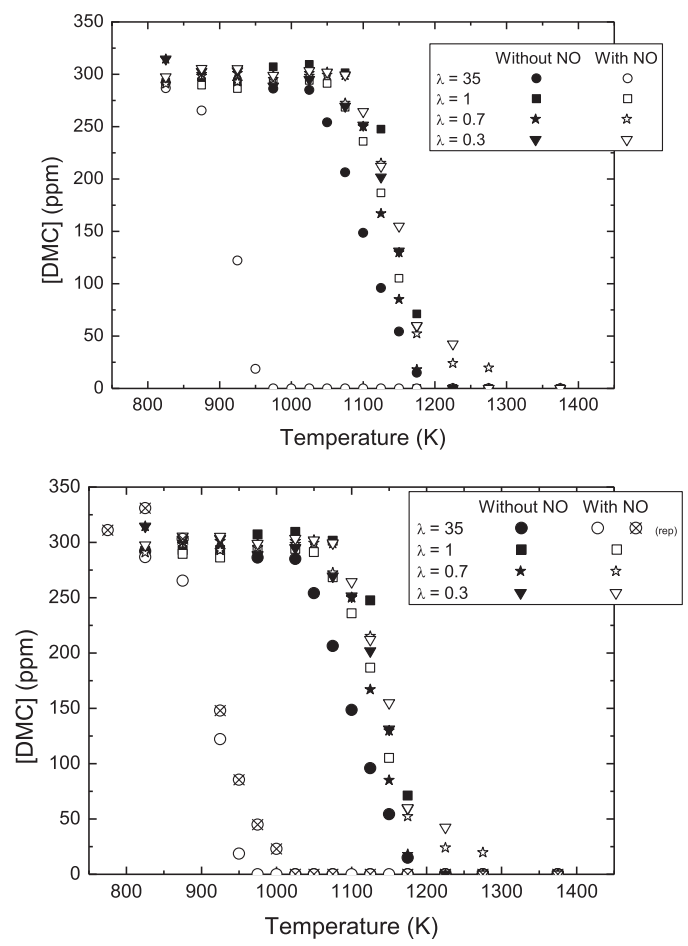

Fig. 3. Influence of the NO presence on the conversion of DMC as a function of temperature and for different stoichiometries. Inlet conditions correspond to sets 2-9 in Table 1. Results of repeated experiments in set 9 (Table 1) conditions are included.

cals able to participate in reburn reactions, and thus 336 can act to remove both NO and the carbon com- 337 pounds from the typical pathways that lead to soot 338 formation [27].

In order to get some more insight of the present 340 results, kinetic modeling of DMC conversion may 341 


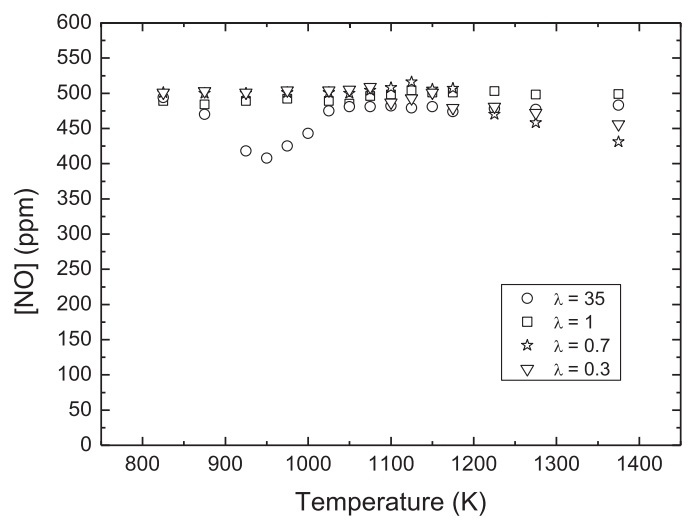

Fig. 4. Conversion of NO during the oxidation of the DMC-NO mixtures, as a function of temperature for different stoichiometries. Inlet conditions correspond to sets 2, 4, 6 and 8 in Table 1 . duction section, not many studies have considered the oxidation of DMC and even less the pyrolysis of this compound, and the subset proposed by Glaude et al. [6] for DMC oxidation, largely based on estimations, has been added to the mechanism developed in our group to simulate the present results. However, the agreement between experiments and calculations is not very good, as seen in Fig. 5 in the comparison of experimental results together with calculations for stoichiometric conditions $(\lambda=1)$. Calculations are shifted around $100 \mathrm{~K}$ toward higher temperatures compared to experimental results.

Analyzing the sensitivity of the mechanism to the different parameters, both kinetic and thermodynamic, calculations appear to be particularly sensitive to the thermodynamic data involved in the DMC reaction subset. Glaude et al. [6] estimated the thermodynamic parameters of DMC and derivatives using CBS-Q methods, and Glaude estimations may involve uncertainty. In order to evaluate the impact and sensitivity of the results to the thermodynamic data used for the calculations, a new estimation has been made in the present work using the methodology proposed by Ritter and Bozzelli through the use of the THERM [31] software. This software uses the group additivity method to estimate the thermodynamic properties of molecules and their radicals. The rules followed to calculate the corresponding thermodynamic properties are based on the proposals by Benson and Buss [32]. The inlet parameters for the calculations are the type and number of groups in the molecule, the number of rotors and, optionally, the number of symmetries. The default symmetry number given by the software, which is 1 , was used for all the molecules studied. The thermodynamic data for the radicals are obtained via its "mother" be helpful. As it has been mentioned in the intro- molecule, by abstracting an atom, for example a hy- 381 drogen, from the desired position in the "mother" 382 molecule.

The thermodynamic data obtained in the 384 present work for the selected species together with 385 the enthalpies of formation given by Glaude et al. 386 [6] are summarized in Table 3. We are aware that 387 the CBS-Q methods are probably more accurate to 388 calculate thermodynamic data. However, the differ- 389 ences compared to Glaude et al. [6] estimations and 390 the sensitivity of model calculations to thermody- 391 namic data found (see discussion below) indicate 392 the importance of being conscious of the impact 393 of thermodynamics and the necessity of more ac- 394 curate determinations.

Figure 5 also includes the modeling results ob- 396 tained using the thermodynamic data calculated in 397 this work with the THERM [31] software. As it 398 can be observed, the chemical-kinetic modeling is 399 very sensitive to the thermodynamics involved in 400 the process. When the thermodynamic data taken 401 from the literature are used, the predicted conver- 402 sion of DMC is shifted toward higher temperatures 403 with respect to the experimental results, whereas 404 the results obtained with the use of the here cal- 405 culated thermodynamic data show that the conver- 406 sion of DMC is shifted to lower temperatures when 407 compared with the experimental results. Therefore, 408 it is clear the sensitivity of the DMC conversion 409 process to the specific thermodynamic data of the 410 DMC derived species.

Considering the results obtained, we performed 412 a sensitivity analysis to the thermodynamics of 413 the process to identify the species whose simu- 414 lation results are more sensitive to. To perform 415 this analysis we have considered the influence of 416 the given formation enthalpy by keeping fixed 417 the rest of thermodynamic parameters. There- 418 fore, considering the results shown in Table 3 and 419 the formation enthalpy values for these species 420 from the literature [6], we have calculated the av- 421 erage enthalpy of formation and observed how 422 the performance of the model is modified when 423 testing each individual species: $\mathrm{CH}_{3} \mathrm{OCOOCH}_{2}, 424$ $\mathrm{CH}_{3} \mathrm{OCOO}$ and $\mathrm{CH}_{2} \mathrm{OCOOH}$. This study has not 425 been conducted with $\mathrm{CH}_{3} \mathrm{OCOOH}$, since the dif- 426 ference between the formation enthalpy value pro- 427 posed in the literature and the one obtained in this 428 study differs in less than $1 \mathrm{kcal} / \mathrm{mol}$, which may lie 429 within the typical uncertainties for enthalpies of 430 formation.

Through this analysis we have identified that the 432 enthalpy of formation of the species $\mathrm{CH}_{3} \mathrm{OCOO} 433$ (MCr) greatly influences the chemical-kinetic mod- 434 eling of the DMC conversion process, and the re- 435 sults are shown in Fig. 6. For the other species, no 436 influence of the given formation enthalpy value was 437 observed. These results limit the uncertainties to 438 the $\mathrm{CH}_{3} \mathrm{OCOO}$ species, for which accurate thermo- 439 dynamic data are needed. 1

38 . (n)

(n)

.

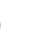

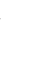

\section{5} 年

.



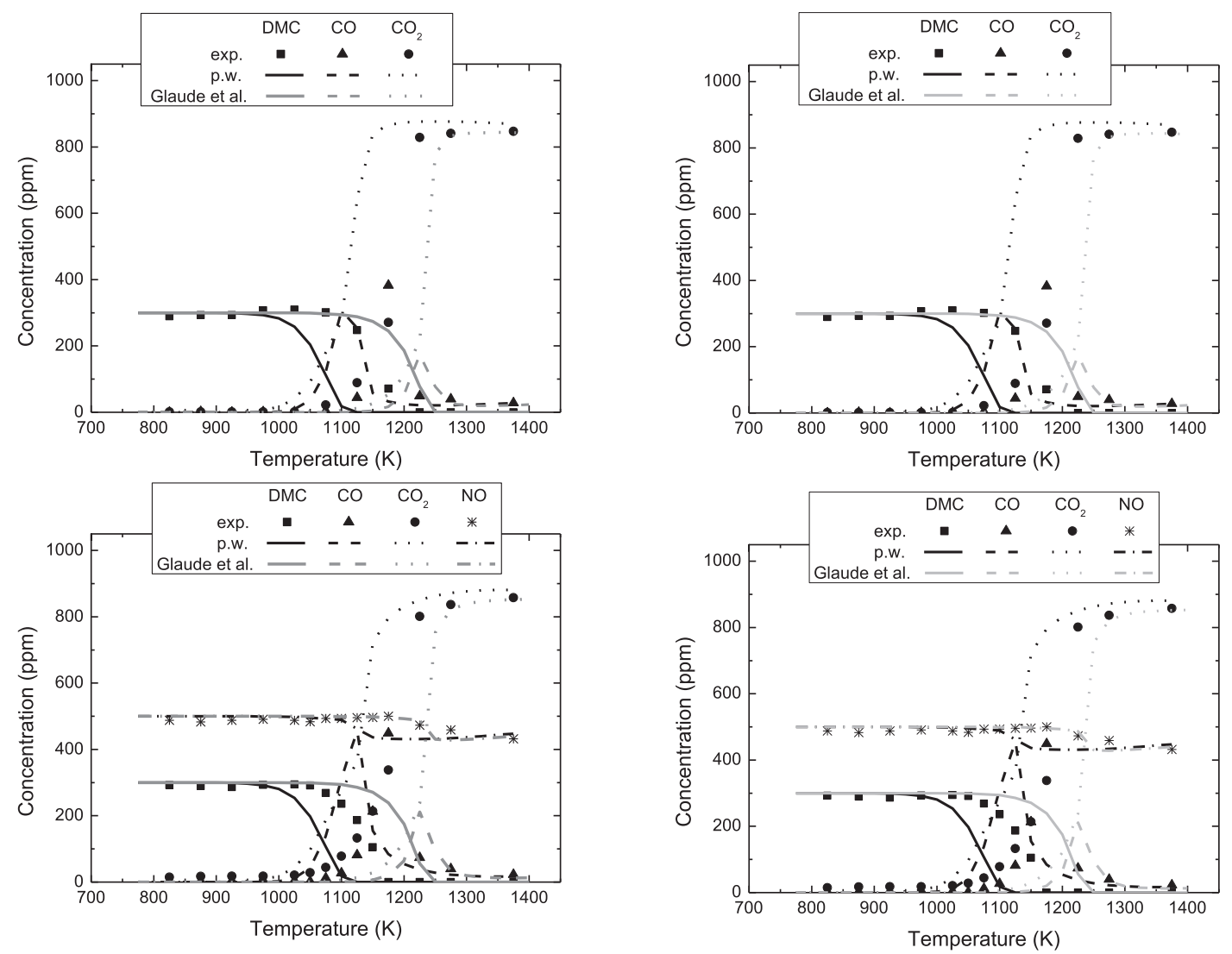

Fig. 5. Comparison of experimental and predicted results of $\mathrm{DMC}, \mathrm{CO}, \mathrm{CO}_{2}$ and $\mathrm{NO}$ as a function of temperature and for stoichiometric conditions $(\lambda=1)$. Lines denote model predictions obtained with the thermodynamics proposed by Glaude et al. [6] (grey lines) and with the thermodynamic data proposed in the present work (black lines). The inlet conditions correspond to sets 5 (upper part) and 6 (bottom part) in Table 1.

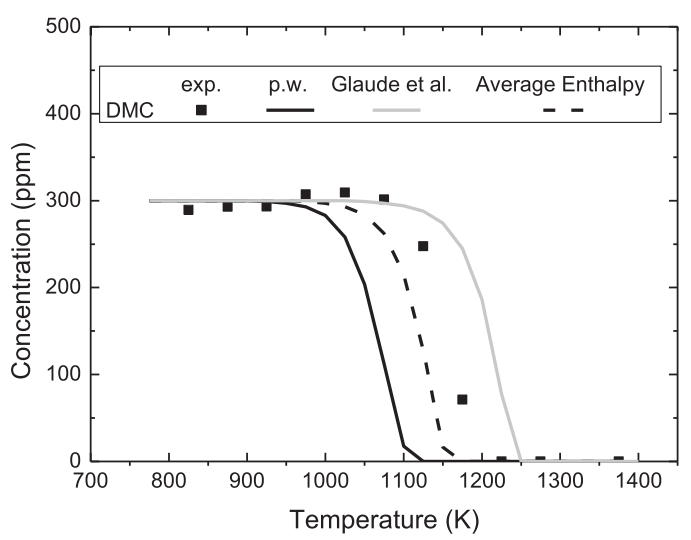

Fig. 6. Comparison of experimental and predicted results of DMC as a function of temperature and stoichiometric conditions $(\lambda=1)$. Lines denote model predictions obtained with different values for the enthalpy of formation of $\mathrm{CH}_{3} \mathrm{OCOO}$. The inlet conditions correspond to set 5 in Table 1.
Despite the uncertainty in the thermodynamic 441 parameters and the impact on the temperature win- 442 dow in which conversion of DMC occurs, we have 443 confirmed that the main reaction pathways are not 444 affected by the thermodynamic data. Thus, the 445 present mechanism can be used to determine the 446 main reaction pathways happening during the con- 447 version of DMC. These results are included as sup- 448 plemental material (SMM-2; Figure S1) together 449 with the sensitivity analysis results (SMM-2; Table 450 1S). Main outcomes are briefly discussed as follows. 451

The results of the reaction rate analysis indi- 452 cate that the initiation reactions involved in the con- 453 version of DMC are not significantly affected by 454 the reaction environment when considering fuel- 455 rich and stoichiometric conditions (Figure S1a). 456 DMC mostly reacts by interaction with $\mathrm{H}$ to yield 457 $\mathrm{CH}_{3} \mathrm{OC}(=\mathrm{O}) \mathrm{OCH}_{2}$, and through its decomposi- 458 tion yielding $\mathrm{CH}_{3} \mathrm{OC}(=\mathrm{O}) \mathrm{O}$ and $\mathrm{CH}_{3}$ radicals. 459 Sensitivity analysis results also indicate that the 460 process is highly sensitive to these two reactions 461 (Table 1S). These intermediate products, through 462 


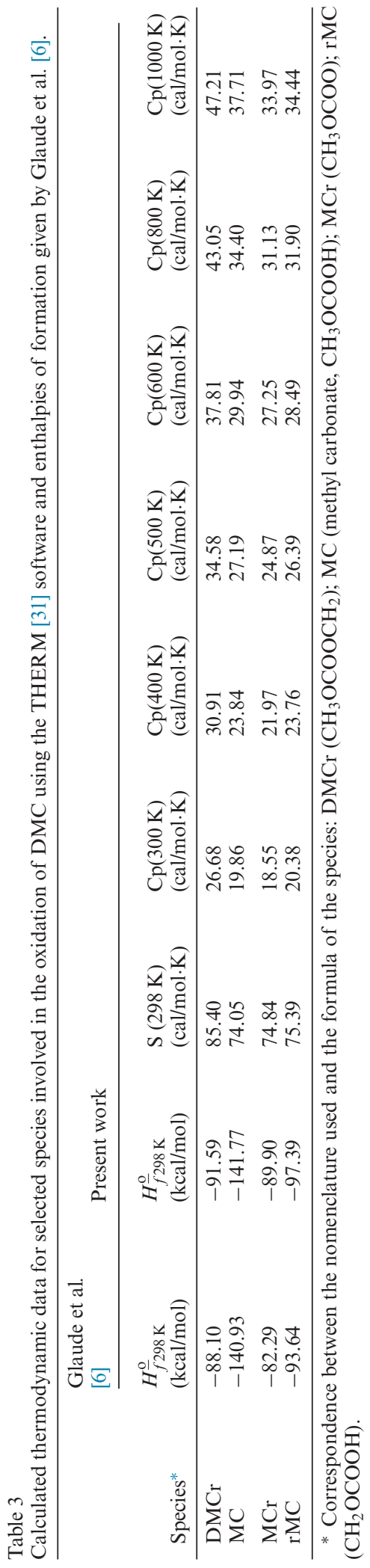

further reactions, produce finally $\mathrm{CO}$ and $\mathrm{CO}_{2}$. It 463 is worth to note the fact that DMC decomposition 464 yields almost directly $\mathrm{CO}$ and $\mathrm{CO}_{2}$, which can be re- 465 lated to the low tendency of DMC to produce soot 466 since pyrolytic conditions will favor this thermal de- 467 composition reaction route.

For fuel lean conditions, Figure S1b, the ini- 469 tiation reactions of DMC conversion differ from 470 those at fuel richer conditions ( $\lambda=1$ and lower). 471 These conditions favor the formation of oxidizing 472 radicals such as $\mathrm{O}$ and $\mathrm{OH}$, which, in addition to 473 $\mathrm{H}$ radicals, are responsible of most of DMC con- 474 sumption. The effect of the increased $\mathrm{O}$ and $\mathrm{OH} 475$ radical pool makes the reaction path that leads to 476 the formation of $\mathrm{CH}_{3} \mathrm{OC}(=\mathrm{O}) \mathrm{OCH}_{2}$ to dominate 477 over the DMC decomposition, resulting in nearly 478 one main initiation reaction, which even takes place 479 at lower temperatures.

Reaction path analysis has also been used to 481 identify the main reactions of the DMC-NO sys- 482 tem. According to this analysis, the presence of 483 $\mathrm{NO}$ provides a new source of $\mathrm{OH}$ radicals at low 484 temperature and in the presence of high $\mathrm{O}_{2}$ con- 485 centrations $(\lambda=35)$. Under these conditions, $\mathrm{NO}$ is 486 converted to $\mathrm{NO}_{2}$ by transforming the less reactive 487 $\mathrm{HO}_{2}$ radicals into the more reactive $\mathrm{OH}$ radicals 488 (r.1). Subsequently, $\mathrm{NO}_{2}$ is converted back into NO 489 through reaction $\mathrm{r} .2$, which also favors the produc- 490 tion of $\mathrm{OH}$ radicals, and reaction r.3.

$$
\begin{aligned}
& \mathrm{NO}+\mathrm{HO}_{2} \rightleftharpoons \mathrm{NO}_{2}+\mathrm{OH} \\
& \mathrm{NO}_{2}+\mathrm{H} \rightleftharpoons \mathrm{NO}+\mathrm{OH} \\
& \mathrm{NO}_{2}+\mathrm{CH}_{3} \rightleftharpoons \mathrm{NO}+\mathrm{CH}_{3} \mathrm{O}
\end{aligned}
$$

Therefore, the promoted OH radical pool is the 492 responsible of the shift to much lower tempera- 493 tures of the onset temperature for the consumption 494 of DMC (Fig. 3), coinciding with the temperature 495 window for the $\mathrm{NO}$ to $\mathrm{NO}_{2}$ conversion (Fig. 4). In 496 fact, DMC is mainly consumed by $\mathrm{OH}$ radicals via 497 r.4, result also supported by the sensitivity analysis 498 results.

$$
\begin{aligned}
& \mathrm{CH}_{3} \mathrm{OC}(=\mathrm{O}) \mathrm{OCH}_{3}+\mathrm{OH} \rightleftharpoons \mathrm{CH}_{3} \mathrm{OC}(=\mathrm{O}) \mathrm{OCH}_{2} \\
& +\mathrm{H}_{2} \mathrm{O}
\end{aligned}
$$

It is worth remarking that the accelerating ef- 500 fect of the NO presence under fuel-lean conditions 501 of DMC conversion is more pronounced than the 502 own effect of the presence of very high $\mathrm{O}_{2}$ concen- 503 trations, indicating the potential of the DMC-NO 504 system, at least under these conditions, for pro- 505 moting the oxidation of DMC under less favorable 506 conditions (i.e. lower temperatures). Nevertheless, 507 it must also be noticed that the participation of NO 508 in this system does not produce the net removal of 509 $\mathrm{NO}_{\mathrm{x}}$.

At high temperatures $(>1175 \mathrm{~K})$ and fuel-rich 511 conditions ( $\lambda=0.3$ and 0.7$)$, a reduction of the con- 512 centration of NO is observed, which is originated 513 


$$
\begin{aligned}
& \mathrm{HCCO}+\mathrm{NO} \rightleftharpoons \mathrm{HCNO}+\mathrm{CO} \\
& \mathrm{HCCO}+\mathrm{NO} \rightleftharpoons \mathrm{HCN}+\mathrm{CO}_{2}
\end{aligned}
$$

HCCO radicals are formed as intermediate products from the conversion of DMC under both stoichiometric and fuel-rich conditions. However, those radicals are only active in removing NO for fuel-rich conditions. Under stoichiometric conditions, a competition between $\mathrm{O}_{2}$ attack and $\mathrm{NO}$ interaction with hydrocarbon radicals occurs, and an increased oxygen presence (from rich to stoichiometric conditions) causes the $\mathrm{HCCO}$ oxidation to be favored compared to its interaction with $\mathrm{NO}$ under the specific operating conditions of the present work, as it has also been observed in previous works of the authors [33].

\section{Conclusions}

A study of DMC conversion at different temperatures and stoichiometries, ranging from pyrolysis to very fuel-lean conditions, has been performed, and the impact of the presence of DMC on soot and $\mathrm{NO}$ emissions is evaluated.

The results indicate that DMC contributes to low soot emissions compared, under given conditions, to classical soot precursors such as acetylene, but also compared to other oxygenates used as soot suppressor additives, such as ethanol.

DMC can also contribute to slightly minimize $\mathrm{NO}$ emission, because a net reduction of $\mathrm{NO}_{x}$ is found when the DMC-NO interaction occurs at fuel-rich conditions. However, no net reduction of $\mathrm{NO}_{x}$ is found for stoichiometric and fuel-lean conditions. The presence of NO is found to sensitize the conversion of DMC under fuel-lean conditions.

The kinetic mechanism compiled for DMC conversion is able to reproduce reasonably well the experimental trends obtained, and the present study has highlighted the importance of thermodynamic data of DMC and derivatives in the modeling of the process of oxidation of DMC, because the simulation results are very sensitive to them.

\section{Acknowledgments}

Authors acknowledge the Aragón Government and the European Social Fund, GPT group, and MINECO and FEDER (Project CTQ2015-65226R) for financial support. Dr. M. Abián acknowledges the MINECO and Instituto de Carboquímica (ICB-CSIC) for the post-doctoral grant awarded (FPDI-2013-16172).
Supplementary materials

Supplementary material associated with this ar- 563 ticle can be found, in the online version, at doi: 564 10.1016/j.proci.2016.07.086.

\section{References}

566

[1] Y. Ren, Z. Huang, H. Miao, et al., Fuel 87 (2008) 567 2691-2697. 568

[2] C.K. Westbrook, W.J. Pitz, H.J. Curran, J. Phys. 569 Chem. A 110 (2006) 6912-6922. 570

[3] P. Pepiot-Desjardins, H. Pitsch, R. Malhotra, 571 S.R. Kirby, A.L. Boehman, Combust. Flame 154572 (2008) 191-205.

[4] C.S. McEnally, L.D. Pfefferle, Environ. Sci. Technol. 574 45 (2011) 2498-2503.

[5] J. Wang, F. Wu, J. Xiao, S. Shuai, Fuel 88 (2009) 576 2037-2045.

[6] P.A. Glaude, W.J. Pitz, M.J. Thomson, Proc. Com- 578 bust. Inst. 30 (2005) 1111-1118.

[7] G.D. Zhang, H. Liu, X.X. Xia, W.G. Zhang, 580 J.H. Fang, Proc. Inst. Mech. Eng. Part D: J. Automob. 581 Eng. 219 (2005) 897-903.

[8] M.A. Pacheco, C.L. Marshall, Energy Fuels 11583 (1997) 2-29.

[9] H. Cui, T. Wang, F. Wang, C. Gu, P. Wang, Y. Dai, 585 J. Supercrit. Fluids 30 (2004) 63-69. 586

[10] R. Saada, S. Kellici, T. Heil, D. Morgan, B. Saha, 587 Appl. Catal. B-Env. 168 (2015) 353-362. 588

[11] T. Murayama, M. Zheng, T. Chikahisa, et al., SAE 589 Technical Papers 952518, 1995.

[12] G. Chen, W. Yu, J. Fu, et al., Combust. Flame 159591 (2012) 2324-2335.

[13] M. Bilde, T.E. Mogelberg, J. Sehested, et al., J. Phys. 593 Chem. A 101 (1997) 3514-3525.

[14] A. Shina, M.J. Thomson, Combust. Flame 136 (2004) 595 548-556.

[15] E. Hu, Y Chen, Z. Zhang, et al., Fuel 140 (2015)626- 597 632.

[16] M. Abián, J. Giménez-López, R. Bilbao, 599 M.U. Alzueta, Proc. Combust. Inst. 33 (2011) 600 317-323.

[17] M.U. Alzueta, M. Borruey, A. Callejas, A. Millera, 602 R. Bilbao, Combust. Flame 152 (2008) 377-386. 603

[18] M.U. Alzueta, J.M. Hernández, Energy Fuels 16604 (2002) 166-171.

[19] P.G. Kristensen, P. Glarborg, K. Dam-Johansen, 606 Combust. Flame 107 (1996) 211-222. 607

[20] M.U. Alzueta, P. Glarborg, K. Dam-Johansen, Com- 608 bust. Flame 109 (1997) 25-36.

[21] M.P. Ruiz, R. Guzmán de Villoria, A. Millera, 610 M.U. Alzueta, R. Bilbao, Ind. Eng. Chem. Res. 46611 (2007) 7550-7560.

[22] A.E. Lutz, R.J. Kee, J.A. Miller, Sandia National 613 Laboratories, Report SAND87-8248, 1988.

[23] R.J. Kee, F.M. Rupley, J.A. Miller, Sandia National 615 Laboratories, Report SAND87-8215, 1991.

[24] P. Glarborg, M.U. Alzueta, K. Dam-Johansen, 617 J.A. Miller, Combust. Flame 115 (1998) 1-27. 618

[25] M. Abián, C. Esarte, A. Millera, R. Bilbao, 619 M.U. Alzueta, Energy Fuels 22 (2008) 3814-3823. $\quad 620$

[26] M. Abián, A. Millera, R. Bilbao, M.U. Alzueta, 621 Combust. Flame 161 (2014) 2288-2296. 622

[27] M. Abián, E. Peribáñez, A. Millera, R. Bilbao, 623 M.U. Alzueta, Combust. Flame 161 (2014) 280-287. 624 
625 [28] E. Esarte, A. Millera, R. Bilbao, M.U. Alzueta, Fuel 626 Process. Technol. 90 (2009) 496-503.

627 [29] C. Esarte, M. Peg, M.P. Ruiz, A. Millera, R. Bilbao, 628 M.U. Alzueta, Ind. Eng. Chem. Res. 50 (2011) 44126294419.

630 [30] G. Dayma, K. Hadj, K.H. Ali, P. Dagaut, Proc. Com631 bust. Inst. 31 (2007) 411-418.
[31] R. Ritter, J.W. Bozzelli, Int. J. Chem. Kinet. 23 (1991) 632 767-778.

633

[32] S.W. Benson, J.H. Buss, J. Chem. Phys. 29 (1958) 634 279-324. 635

[33] M. Abián, S.L. Silva, A. Millera, R. Bilbao, 636 M.U. Alzueta, Fuel Process. Technol. 91 (2010) 1204- 637 1211. 